\title{
Diversity of plasmids and Tn1546-type transposons among VanA Enterococcus faecium in Poland
}

\author{
E. Wardal $^{1}$ • A. Kuch $^{2}$ - I. Gawryszewska ${ }^{1}$ - D. Żabicka ${ }^{2}$-W. Hryniewicz ${ }^{2} \cdot$ E. Sadowy $^{1}$
}

Received: 21 June 2016 / Accepted: 26 September 2016 / Published online: 17 October 2016

(C) The Author(s) 2016. This article is published with open access at Springerlink.com

\begin{abstract}
The objective of this study was to investigate the antimicrobial resistance, Tn1546 transposon variability and plasmid diversity among Polish vancomycin-resistant Enterococcus faecium (VREfm) isolates of VanA phenotype in the context of their clonal structure. Two hundred sixteen clinical VREfm isolates collected between 1997 and 2010 were studied by antimicrobial susceptibility testing, MLST, MLVA and detection of IS16, esp $p_{\mathrm{Efm}}$, pilA, intA and plasmid-specific genes by PCR. Tn1546 structure was revealed by overlapping PCR and sequencing. Selected isolates were subjected to PFGE-S1 and Southern hybridization analyses. The vast majority of the isolates $(95.8 \%)$ belonged to lineages 17/18 (during the whole study period 1997-2010) and 78 (mostly in 2006-2010) of hospital-adapted meroclone of E. faecium. All isolates displayed a multi-drug resistance phenotype. Twenty-eight Tn1546 types (including 26 novel ones) were associated with eight different ISs (IS1216, IS1251, ISEfa4, ISEfa5, ISEfm2, ISEf1, IS3-like, ISEfm1like). The vanA-determinant was typically located on plasmids, which most commonly carried rep $2_{\mathrm{pRE} 25}$, rep $17_{\mathrm{pRUM}}$, rep $18_{\mathrm{pEF} 418}$, rep $1_{\mathrm{pIP} 501}, \omega-\varepsilon-\zeta$ and axe-txe genes. VanA isolates from 1997-2005 to 2006-2010 differed in clonal composition, prevalence of gentamicin- and tetracycline-
\end{abstract}

Electronic supplementary material The online version of this article (doi:10.1007/s10096-016-2804-8) contains supplementary material, which is available to authorized users.

E. Sadowy

ewasadowy@cls.edu.pl

1 Department of Molecular Microbiology, National Medicines Institute, Chełmska 30/34, 00-725 Warsaw, Poland

2 Department of Epidemiology and Clinical Microbiology, National Medicines Institute, Chełmska 30/34, 00-725 Warsaw, Poland resistance and plasmidome. Our analysis revealed high complexity of Tn1546-type transposons and vanA-plasmids, and suggested that diverse genetic events, such as conjugation transfer, recombination, chromosomal integration and DNA mutations shaped the structure of these elements among Polish VREfm.

\section{Introduction}

In the past 20 years, vancomycin-resistant enterococci (VRE) have emerged as nosocomial pathogens worldwide. In Poland, the first VRE outbreak due to Enterococcus faecium (VREfm) of VanA phenotype started in December 1996 in the Gdańsk Medical University [1]. The vast majority of VREfm observed worldwide belongs to a specific hospital meroclone, initially described as clonal complex 17 (CC17), later divided into three distinct lineages 17,18 and 78 based on multilocus sequence typing (MLST) analyses [2, 3]. Recently, the approach called Bayesian Analysis of Population Structure (BAPS), applied to the E. faecium MLST data delimited two groups within the hospital meroclone, 2-1 and 3-3, corresponding to lineages 78 and $17 / 18$, respectively [4]. Strains belonging to the hospital meroclone are ciprofloxacin- and ampicillin-resistant, enriched in putative virulence traits, and show a distinct genetic repertoire, including cell surface protein genes $(f m s)$, regulatory genes, putative pathogenicity islands, plasmids, insertion sequences (IS) and integrated phages, which promote their adaptation [5-7]. The presence of IS16 and the E. faecium-specific esp gene $\left(e s p_{\mathrm{Efm}}\right)$, carried on the integrative conjugative element ICEEfm 1, together with the intA integrase gene, are 
proven molecular markers of hospital-associated E. faecium [8-10].

Several glycopeptide-resistance phenotypes have been described so far, with VanA and VanB being the most common in enterococci isolated from hospital infections [11]. The vanA gene cluster is carried on Tn1546-type transposons [12], which show a significant degree of heterogeneity, associated with presence of point mutations, deletions and presence of various ISs [13, 14]. A few studies demonstrated the location of Tn1546 on Inc18, pRUM-like, pMG1-like, and pLG1 plasmids $[15,16]$; however, the knowledge of vanA-plasmids and their epidemiology is still far from being satisfactory and may differ significantly among countries.

In Poland, hospital VRE isolates are continuously submitted for confirmation and further analyses to the National Reference Centre for Susceptibility Testing (NRCST), located at the National Medicines Institute in Warsaw. The aim of this study was to characterize E. faecium VanA isolates collected by the NRCST since 1997 until the end of 2010, focusing on the $\mathrm{Tn} 1546$ transposon variability and vanA-plasmid diversity in the context of the clonal structure of VREfm isolates to provide the country-wide picture of these important hospital pathogens.

\section{Materials and methods}

\section{Bacterial isolates and susceptibility testing}

The study comprised 216 consecutive, non-repetitive (1 isolate per patient) VREfm VanA isolates received by the NRCST from 42 hospitals in 24 cities in Poland over the period 1997-2010. Part of the isolates analyzed in this work correspond to strains partially tested in previous surveillance studies, including: 108 VanA representatives of the VREfm collection from 1997 to 2005 [17] and 20 representative isolates of a E. faecium VanA outbreak in 2009 [18]. The majority of isolates $(n=137)$ were derived from 11 VanA outbreaks and the remaining 79 isolates were reported as single isolations. Of the 216 isolates, $211(97.7 \%)$ were from hospitalized patients and five $(2.3 \%)$ were from the hospital environment. Among the isolates from hospitalized patients, a total of 37 isolates $(17.5 \%)$ were from invasive infections ( 31 isolates from blood and 6 from other sources); 52 isolates $(24.6 \%)$ were from non-invasive infections (21 from urine, 18 from wounds, and 13 from other sources) and $122(57.8 \%)$ represented faecal carriage. Antimicrobial susceptibility of 88 isolates, not investigated previously, was tested by the Etest method (bioMérieux, Marcy l'Etoile, France) for daptomycin, teicoplanin and vancomycin and by a broth microdilution method [19] for the remaining compounds
(Table 1). Multidrug-resistant (MDR) isolates were defined as recommended [20]. Vancomycin-resistance determinants were detected by PCR as described previously [21] with the E. faecium BM4147 and E. faecalis V583 strains as positive vanA and vanB controls, respectively.

\section{DNA isolation and genotyping of isolates}

Total DNA of isolates was extracted using Genomic DNA Prep Plus kit (A\&A Biotechnology, Gdansk, Poland). Multilocus VNTR analysis (MLVA), MLST, and detection of 19 rep families and the unique rep $p_{\mathrm{pMG} 1}$ gene were performed as described [22-24]. Sequence types (STs) were grouped to $\mathrm{CCs}$ by the comparative eBURST analysis performed against the whole E. faecium MLST database. PCR

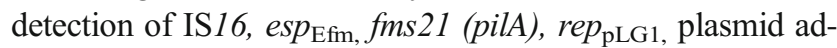
diction systems, relaxase genes, and $i n t A_{\mathrm{ICEEfm} 1}$ was performed as described (Supplementary Table 1 and references therein). DNA of enterococcal isolates from our laboratory collection $[17,18,25]$ served as positive controls.

\section{Plasmid profiling, hybridization analyses, Tn1546 typing and statistical analysis}

DNA in agarose plugs was obtained as described [21], treated with S1 nuclease (Takara Bio, Japan) and separated by PFGE with Lambda Ladder PFG marker (New England Biolabs, Beverly, MA) [26] followed by blotting onto the Hybond membrane (GE Healthcare, Buckinghamshire, UK) by capillary transfer. Hybridization was carried out using the Amersham ECL Random-Prime Labelling and Detection System (GE Healthcare, Buckinghamshire, UK). Tn1546 transposon was investigated by PCR mapping and sequencing (Supplementary Table 1 and references therein) of selected regions encompassing 7571 bp out of 10851 bp (i.e., 70 \% of the transposon, Fig. 1). The Tn1546 sequence of E. faecium BM4147 (GenBank acc. no.: M97297) [12] was used as a reference. The nomenclature of Tn1546-type transposons in the present study was based on the following alphanumeric code: the 'A' types (A1-A6) referred to transposon variants of the wild type (wt) Tn1546 structure (A1) not interrupted by insertion sequences; the ' $\mathrm{B}$ ' types contained 1-3 copies of IS1216 (B, BB, BBB types); the C, D, E, F, G, H and I types carried IS1251, ISEfa5, ISEfa4, ISEfm2, ISEf1, ISEfm1-like and IS3-like elements, respectively. Transposons with more than one IS type were described by a two-, three- or fourletter code (e.g., 'BC' with both IS1216 and IS1251). The Arabic numerals indicated differences in the presence of particular point mutations as well as the orientation of ISs and the localization of their insertion sites (e.g., B1-B4). The novel ISEfm 1-like sequence was submitted to GenBank 
Table 1 MIC values for E. faecium VanA isolated in Poland during the period 1997-2010

\begin{tabular}{|c|c|c|c|c|c|c|c|c|c|}
\hline \multirow[t]{2}{*}{ Compound/phenotype } & \multirow{2}{*}{$\begin{array}{l}1997-2010 \\
\mathrm{~N}=216 \\
\text { Number }(\%) \\
\text { non-susceptible }\end{array}$} & \multicolumn{3}{|l|}{$\begin{array}{l}1997-2005 \\
N=128\end{array}$} & \multicolumn{3}{|l|}{$\begin{array}{l}2006-2010 \\
N=88\end{array}$} & \multicolumn{2}{|c|}{$\begin{array}{l}\text { MIC breakpoints/ } \\
\text { ECOFF }(\mu \mathrm{g} / \mathrm{ml})\end{array}$} \\
\hline & & $\begin{array}{l}\text { Number }(\%) \\
\text { non-susceptible }\end{array}$ & $\begin{array}{l}\mathrm{MIC}_{50} \\
(\mathrm{mg} / \mathrm{l})\end{array}$ & $\begin{array}{l}\mathrm{MIC}_{90} \\
(\mathrm{mg} / \mathrm{l})\end{array}$ & $\begin{array}{l}\text { Number }(\%) \\
\text { non-susceptible }\end{array}$ & $\begin{array}{l}\mathrm{MIC}_{50} \\
(\mathrm{mg} / \mathrm{l})\end{array}$ & $\begin{array}{l}\mathrm{MIC}_{90} \\
(\mathrm{mg} / \mathrm{l})\end{array}$ & $\mathrm{S} \leq$ & $\mathrm{R}>$ \\
\hline Vancomycin ${ }^{\mathrm{a}}$ & $216(100)$ & $128(100)$ & 512 & $>512$ & 88 (100) & $>256$ & $>256$ & 4 & 4 \\
\hline Teicoplanin ${ }^{\mathrm{a}}$ & $216(100)$ & $128(100)$ & 64 & 128 & $88(100)$ & 48 & $>256$ & 2 & 2 \\
\hline Ampicillin $^{\mathrm{a}}$ & $215(99.5)$ & $128(100)$ & $>128$ & $>256$ & $87(98.8)$ & 128 & $>256$ & 4 & 8 \\
\hline $\mathrm{HLGR}^{\mathrm{a}}$ & $172(79.6)$ & $118(92.2)$ & $>1024$ & $>1024$ & $54(64.4)$ & $>1024$ & $>1024$ & 128 & 128 \\
\hline $\operatorname{HLSR}^{\mathrm{a}}$ & $167(77.3)$ & $112(87.5)$ & $>1024$ & $>2048$ & $55(62.5)$ & $>1024$ & $>2048$ & 512 & 512 \\
\hline HLAR ${ }^{28}$ & $147(68.1)$ & $110(86)$ & $>1024$ & $>1024$ & $37(42)$ & $>1024$ & $>2048$ & - & - \\
\hline $\begin{array}{l}\text { Quinupristin/ } \\
\text { dalfopristin }^{\mathrm{a}}\end{array}$ & $2(0.9)$ & $1(0.8)$ & 1 & 2 & $1(1.1)$ & 1 & 1.5 & 1 & 4 \\
\hline Linezolid $^{\mathrm{a}}$ & $1(0.5)$ & $0(0)$ & 1 & 4 & $1(1.1)$ & 1 & 2 & 4 & 4 \\
\hline Tigecykline $^{\mathrm{a}}$ & $0(0)$ & $0(0)$ & 0.06 & 0.19 & $0(0)$ & 0.06 & 0.25 & 0.25 & 0.5 \\
\hline Tetracycline $^{\mathrm{b}}$ & $135(62.2)$ & 89 (68.9) & 64 & 128 & $46(52.3)$ & 8 & 128 & 4 & 4 \\
\hline Ciprofloxacin $^{\mathrm{b}}$ & $215(99.5)$ & $127(99.2)$ & 128 & $>256$ & $88(100)$ & 128 & 256 & 4 & 4 \\
\hline Daptomycin ${ }^{\mathrm{b}}$ & $0(0)$ & $0(0)$ & 2 & 3 & $0(0)$ & 2 & 3 & 4 & 4 \\
\hline Chloramphenicol $^{\mathrm{c}}$ & $53(24.4)$ & $30(23.2)$ & 8 & 16 & $23(26.1)$ & 8 & 16 & 8 & $\geq 32^{\mathrm{c}}$ \\
\hline $\mathrm{MDR}^{28}$ & $216(100)$ & $128(100)$ & $\mathrm{nc}$ & $\mathrm{nc}$ & $88(100)$ & $\mathrm{nc}$ & $\mathrm{nc}$ & - & - \\
\hline
\end{tabular}

$n c$ not calculated, $n$ number of isolates

The results were interpreted following the European Committee on Antimicrobial Susceptibility Testing (EUCAST)-approved breakpoints [53] and the Ecological Cut-Off (ECOFF) values for compounds without defined breakpoints (http://mic.eucast.org/Eucast2/, last accessed 20th July 2015). For chloramphenicol the Clinical and Laboratory Standards Institute (CLSI) breakpoints were used [19] ${ }^{\mathrm{a}}$ Interpretation according to the EUCAST clinical breakpoint value ${ }^{\mathrm{b}}$ Interpretation according to the EUCAST Ecological Cut-off (ECOFF) value ${ }^{\mathrm{c}}$ Interpretation according to CLSI breakpoint value

(KT719407). Chi-square test was used to assess the differences of distributions, with $p \leq 0.05$ considered significant.

\section{Results}

\section{Susceptibility to antimicrobial agents}

All isolates were resistant to vancomycin and teicoplanin (Table 1) and carried vanA. Resistance to ampicillin, ciprofloxacin, tetracycline, chloramphenicol, gentamicin and streptomycin (high level) was prevalent or highly prevalent and all isolates showed the MDR phenotype. A significant decline in the prevalence of both tetracycline-resistance (from 68.9 to $52.3 \%, p=0.01$ ) and high-level gentamicin resistance (from 92.1 to $64.4 \%, p<0.0001)$ was found between the 1995 2005 and 2006-2010 periods. A single isolate was resistant to linezolid and two isolates to quinupristin/dalfopristin. All isolates were susceptible to tigecycline and daptomycin.

\section{MLVA, MLST, IS16 and virulence markers detection}

MLVA was performed for 196 isolates and these results were analysed together with data obtained earlier for 20 isolates from the 2009 outbreak [18]. Among 216 isolates, 37 different
MLVA types (MTs) and three incomplete profiles (due to lack of VNTR7 amplification) were observed, that included 207 and nine isolates, respectively (Supplementary Table 2). MT1, MT159, MT25 and MT13 were most prevalent, with 36, 34, 26 and 20 isolates, respectively. All MT159 isolates except one were isolated in 2006-2010 ( $p \leq 0.0001)$, in contrast to isolates of MT25, which all except one were isolated in 1997-2005 $(p=0.0001)$. The MT1 isolates showed a similar frequency over the whole study period (13.2\% vs $21.6 \%, p=0.07)$. In the present study, STs and the presence of IS16, esp $p_{\mathrm{Efm}}$, intA and pilA were determined for 88 isolates not encompassed by the previous studies (i.e., 68 isolates from 2006 to 2010 and 20 isolates from 2001 to 2002), and these results were analysed with the data obtained previously for the remaining 128 isolates. Altogether, 40 different STs were found, with 18 STs $(45.0 \%)$ represented by single isolates. The vast majority of the STs, i.e. 36 STs representing 207 isolates (95.8\%), belonged to the hospital-adapted meroclone of E. faecium; lineage 17/18 included 31 STs with 165 isolates and was present during the whole period 1997-2010, while lineage 78 included five STs characteristic for 42 isolates, occurring mostly in 2006-2010 ( $p \leq 0.0001)$. IS16 was present in 207 (95.8\%) isolates and $186(86.1 \%)$ isolates harboured the $e s p_{\mathrm{Efm}}$ gene. The integrase gene intA and the pilA gene were found in 181 (83.8\%) and $214(99.1 \%)$ isolates, respectively. 

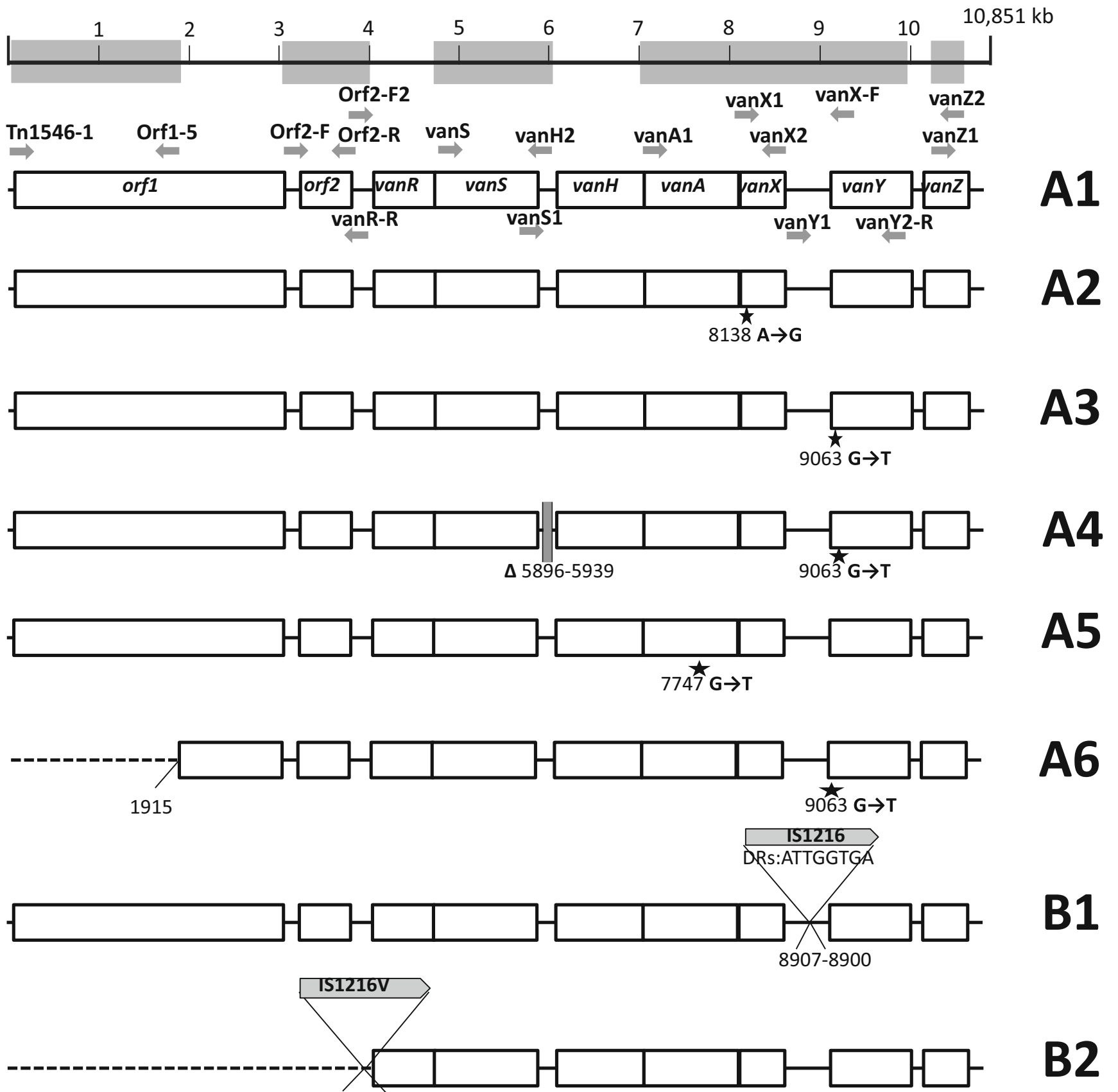

nd. 3902

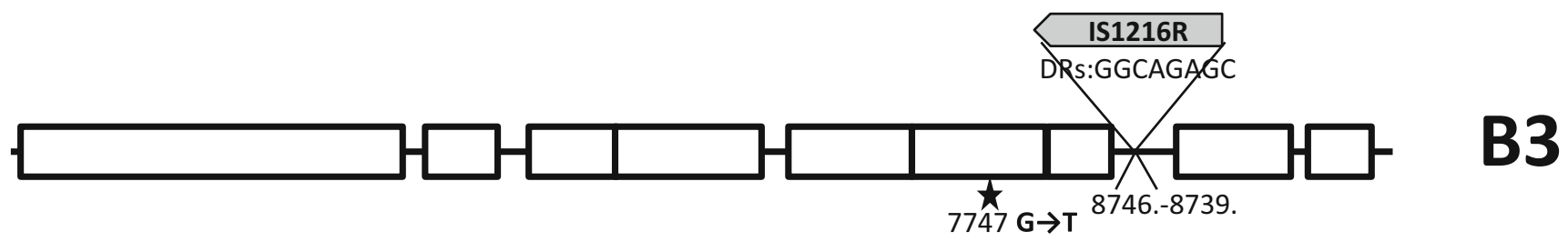

Fig. 1 Diversity of Tn1546 transposon types among E. faecium VanA isolates. Position of primers used in PCR mapping and sequencing indicated by arrows with primer names; open rectangles, transposon genes; stars, positions of point mutations; analyzed areas of the transposon shadowed; dashed lines, deletions in the left arm of the transposon; filled rectangles, deletions within the transposon; vertical arrow, triangles with arrows, the IS positions; single-nucleotide insertion in $\operatorname{van} Y$ 

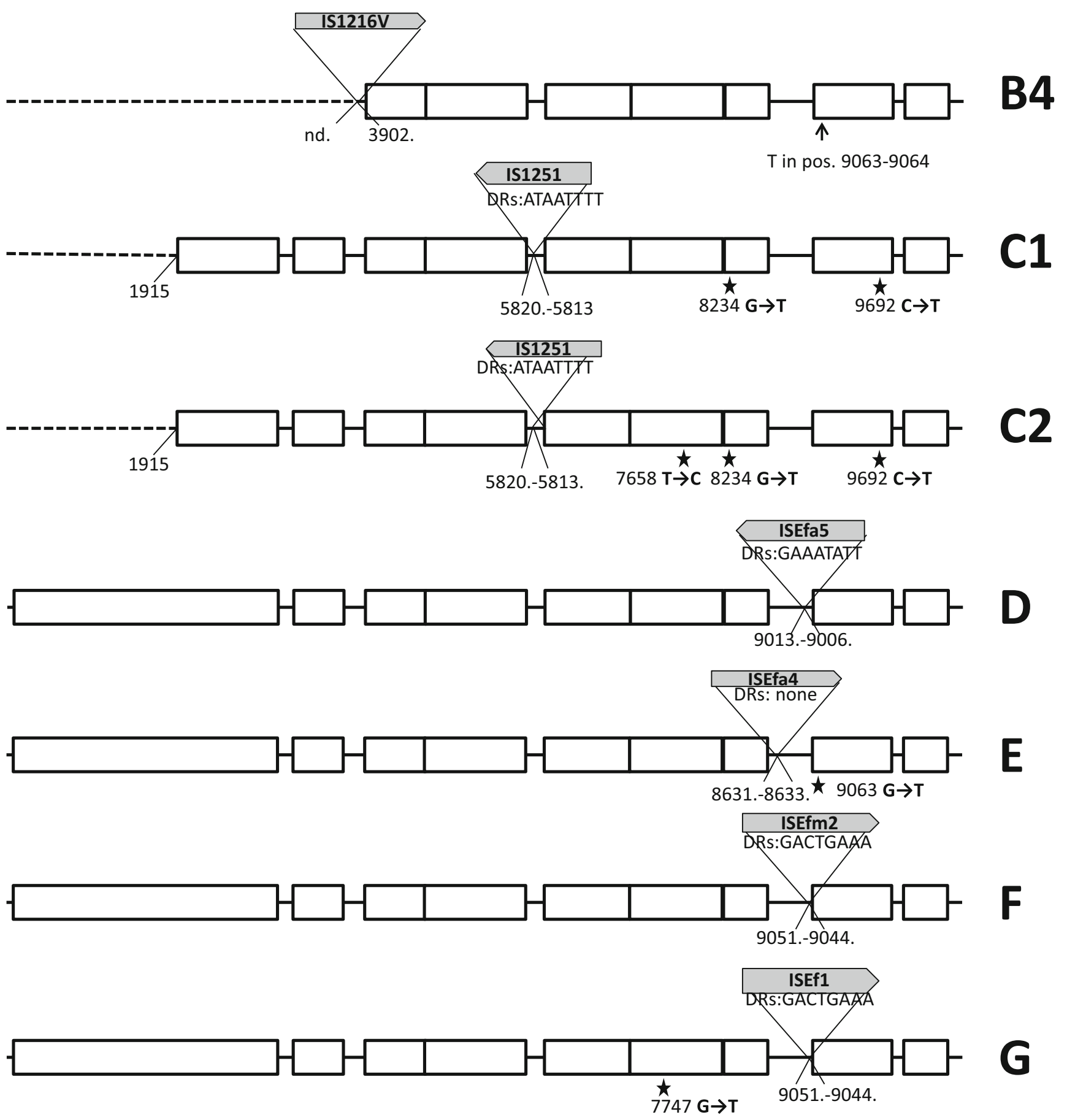

Fig. 1 continued.

\section{Structural diversity of $\operatorname{Tn} 1546$ transposons}

The structure of Tn1546-type transposons was determined for 187 isolates while for 20 isolates the structure of the transposon (representing types A1 and G, Fig. 1) had been published earlier [18]. In the case of nine isolates the structure of the transposon could not be determined in spite of repeated attempts due to lack of PCR products for some parts of the transposon, which might have been caused by sequence polymorphism(s) within PCR primers annealing sites, and discrepancies of sequencing results in certain regions, likely associated with the presence of 

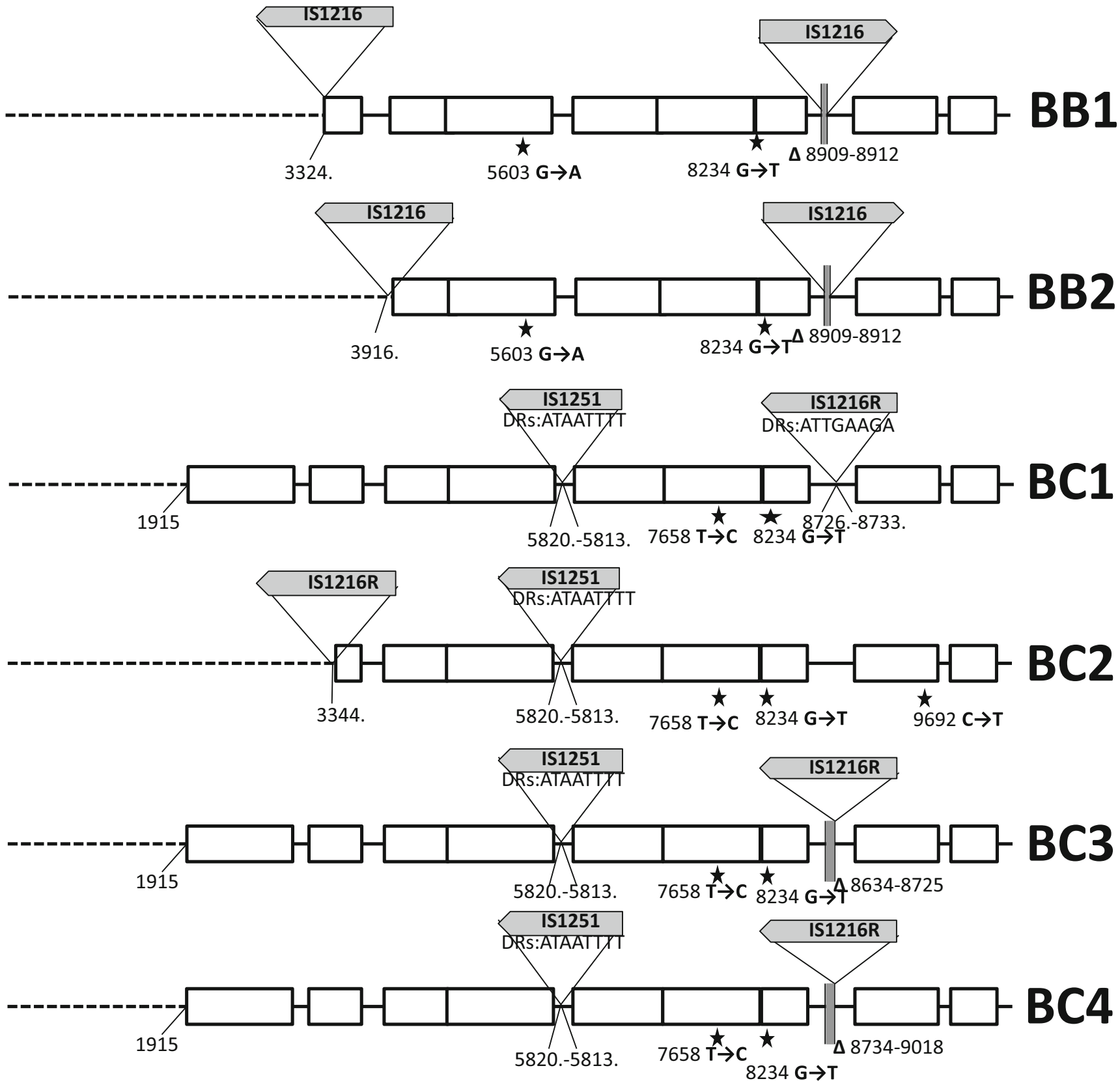

Fig. 1 continued.

more than one transposon in a single isolate. Twenty-eight transposon types, including 26 new ones, were discerned in the analyzed group (Fig. 1). The most predominant types, including $\mathrm{C} 1$ (40 isolates), B2 $(n=38), \mathrm{A} 3(n=$ $36), \mathrm{G}(n=25), \mathrm{E}(n=14), \mathrm{A} 1(n=13)$ and $\mathrm{D}(n=7)$, were associated with several STs and typically showed a multicenter distribution. Eight different ISs were detected within Tn1546, including IS 1216, IS 1251, ISEfa4, ISEfa5, ISEfm2, ISEf1, IS3-like and ISEfm1-like. The most common IS1216 was present in all 16 B-type transposons, both in the direct and reversed orientations, with five different types of 8-bp direct repeats. These B-type transposons were found in Gdańsk and Warsaw, as well as in 14 other cities. IS 1251 was associated with seven Tn1546 types (C1-C2, BC1-BC5) and present in 53 isolates $(25.6 \%)$, which mainly originated from Kraków and Warsaw. In these isolates, IS1251 was always inserted in the vanS-vanH intergenic region of the transposon at the position 5813. The D, E, F and $\mathrm{G}$ types of transposon were characterized by the presence of ISEfa5, ISEfa4, ISEfm 2 and ISEf1 in the vanX-vanY intergenic region, respectively. These types were generally limited to one or two centres, with the exception of the G type, which apart from the outbreak in two Warsaw hospitals [18] 

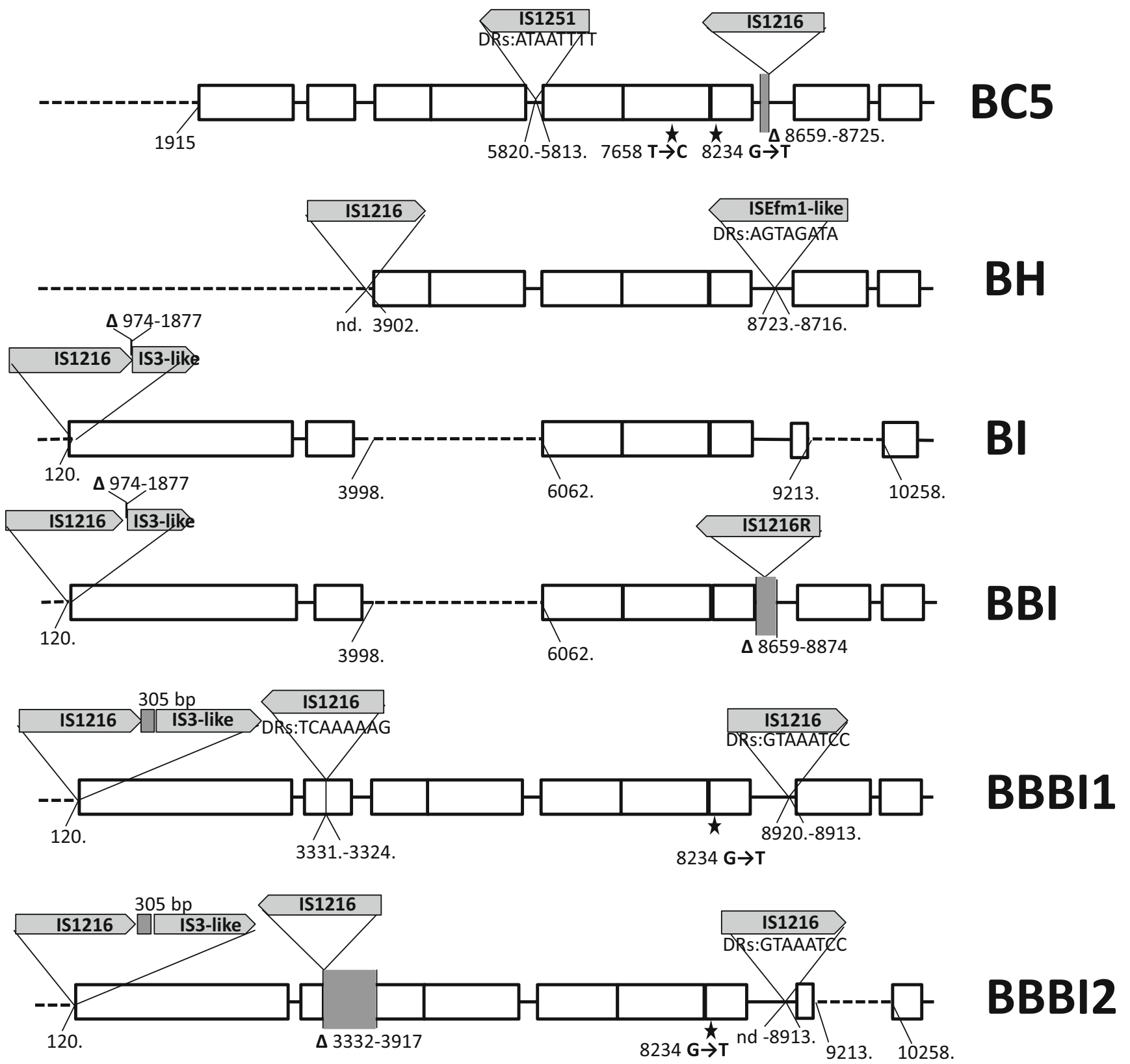

Fig. 1 continued.

occurred in seven other centres. An insertion of an IS in $98 \%$ identical to ISEfml (GenBank no. AF138282) in the van $X$-van $Y$ intergenic region resulted in the BH-type of transposon.

The variability of $\operatorname{Tn} 1546$ was additionally associated with the presence of deletions, insertions and point mutations. In the A4 type, a $44 \mathrm{nt}$ deletion in the vanSvanH intergenic region (nt 5896-5939) was observed. Other deletions, located in orf2, vanX and the $\operatorname{van} X$ van $Y$ intergenic region coincided with the presence of ISs (six types: BB1, BB2, BC4, BC5, BBI, BBBI2). Seven different point mutations were detected, including four known previously (T7658C, G7747T, G8234T, C9692T) [18, 27, 28] and three new ones (G5603A, A8138G and G9063T). The G5603A mutation resulted in the A80T change in VanS and the G9063T mutation in the L4F change in VanY. The B4 type, found in two independent isolates, demonstrated the presence of a novel single-nucleotide $\mathrm{T}$ insertion between nt 90639064 within the van $Y$ gene, resulting in translational frameshift and a truncated VanY. Nevertheless, these two isolates showed high MIC values for vancomycin $(>512 \mathrm{mg} / \mathrm{L}$ in both cases) and teicoplanin (64 and $>128 \mathrm{mg} / \mathrm{L})$. 


\section{Plasmid gene content among VREfm and diversity of vanA-plasmids}

PCR-based typing of plasmid replication initiator genes (rep) was performed for 196 isolates and these results were combined with the data for 20 isolates, published previously [18]. Altogether, ten rep-types were observed among VREfm-VanA (Fig. 2). Isolates carried from one up to seven different rep genes, with 4.7 rep genes per isolate on average. Isolates positive for rep $1_{\mathrm{pIP} 501}$, rep $7_{\mathrm{pT} 181}$ and $r e p_{\mathrm{pMG} 1}$ appeared mainly in the period 1997-2005, while rep $11_{\mathrm{pEF} 1071}$ gene was typical for isolates obtained in 2006-2010. The plasmid stabilization systems axe-txe and rep 17 pRUM were present in the majority of isolates. Another system, $\omega-\varepsilon-\zeta$, was also quite common, predominantly among rep 2 pRE 25 -carrying strains, and occurred mainly in the period of 2006-2010. Two additional systems, mazEF and relBE, were observed only in 2003 for six and two isolates, respectively. The $\operatorname{rel}_{\mathrm{pCIZ} 2}$ and $r e l_{\mathrm{pEF} 1}$ relaxase genes were prevalent, and additionally $r e l_{\mathrm{pHT \beta}}$ and $r e l_{\text {pRE25 }}$ were detected. The majority of $r e l_{\text {pRE25-positive iso- }}$ lates $(n=22,91.7 \%)$ were also rep $2_{\mathrm{pRE} 25}$-positive, however, most of 169 rep $2_{\mathrm{pRE} 25}$-positive isolates lacked this relaxase. Isolates carrying $\mathrm{rel}_{\mathrm{pHT \beta}}$ dominated in 1997-2005 (40 out of $45 \mathrm{rel}_{\mathrm{pHT \beta}}$-positive isolates) and the majority of $r e l_{\mathrm{pHT \beta}}-$ positive isolates also harboured rep pMG1 $(n=43,95.5 \%)$.

Fifty-two isolates, obtained from 24 medical centres over the whole study period and representing 26 different STs and 21 Tn1546 types were selected for PFGE of S1-digested DNA and hybridization analyses. Additionally, the results obtained previously for three isolates from the 2009 outbreak [18] were included for comparative purposes. Investigated isolates showed the presence from one up to 11 plasmid bands per isolate in PFGE-S1 analyses. Subsequent hybridization with the vanA probe revealed the presence of 86 vanA-plasmids with up to four such plasmids in an isolate, and two cases of chromosomal localization of vanA (Table 2). Further hybridization studies showed the co-localization of vanA determinants with all six tested rep types, including rep $2_{\mathrm{pRE} 25}$, rep $17_{\mathrm{pRUM}}$, rep $18_{\mathrm{pEF} 418}$, rep $1_{\mathrm{pIP} 501}, r e p_{\mathrm{pLG} 1}$ and $r e p_{\mathrm{pMG} 1}$ that accounted for $40.7 \%(n=35), 40.7 \%(n=35), 24.4 \%(n=$ $21), 19.8 \%(n=17), 5.8 \%(n=5)$ and $1.2 \%(n=1)$ of vanAplasmids, respectively. The vanA-plasmids with rep $1_{\mathrm{pIP} 501}$ were limited to isolates from 1997 to 2005, circulating in two hospitals in Poznań. These plasmids differed by size (from ca. 30 to ca. $265 \mathrm{~kb}$ ) and presence of other rep and toxin-antitoxin genes, and carried four different types of Tn1546, with A3 being predominant ( 8 out of 13 isolates harbouring vanA-plasmids with rep $\left.1_{\text {pIP501 }}\right)$. The vanA-plasmids with rep $2_{\mathrm{pRE} 25}$, rep $17_{\mathrm{pRUM}}$ and rep $18_{\mathrm{pEF} 418}$ genes showed a multicentre distribution and occurred during the whole study period. In total, 37 (43\%) vanA-plasmids were associated with more than a single rep type and 21 vanA-plasmids (24.4\%), present in 11 isolates, did not hybridize with any of the tested rep genes. With a single exception, these latter plasmids were obtained during 2006-2010 ( $p=$ $0.001)$. Five of the isolates with these unknown replicons concomitantly carried three vanA-plasmids, ca. 30, 160 and $380 \mathrm{~kb}$ in size, which did not hybridize with any probes of toxin-antitoxin and relaxase genes tested. All these isolates carried B2 transposons, but belonged to diverse STs and MTs, and originated from four different medical centres over 2006-2010. Two toxin-antitoxin systems, $\omega-\varepsilon-\zeta$ and axe-txe

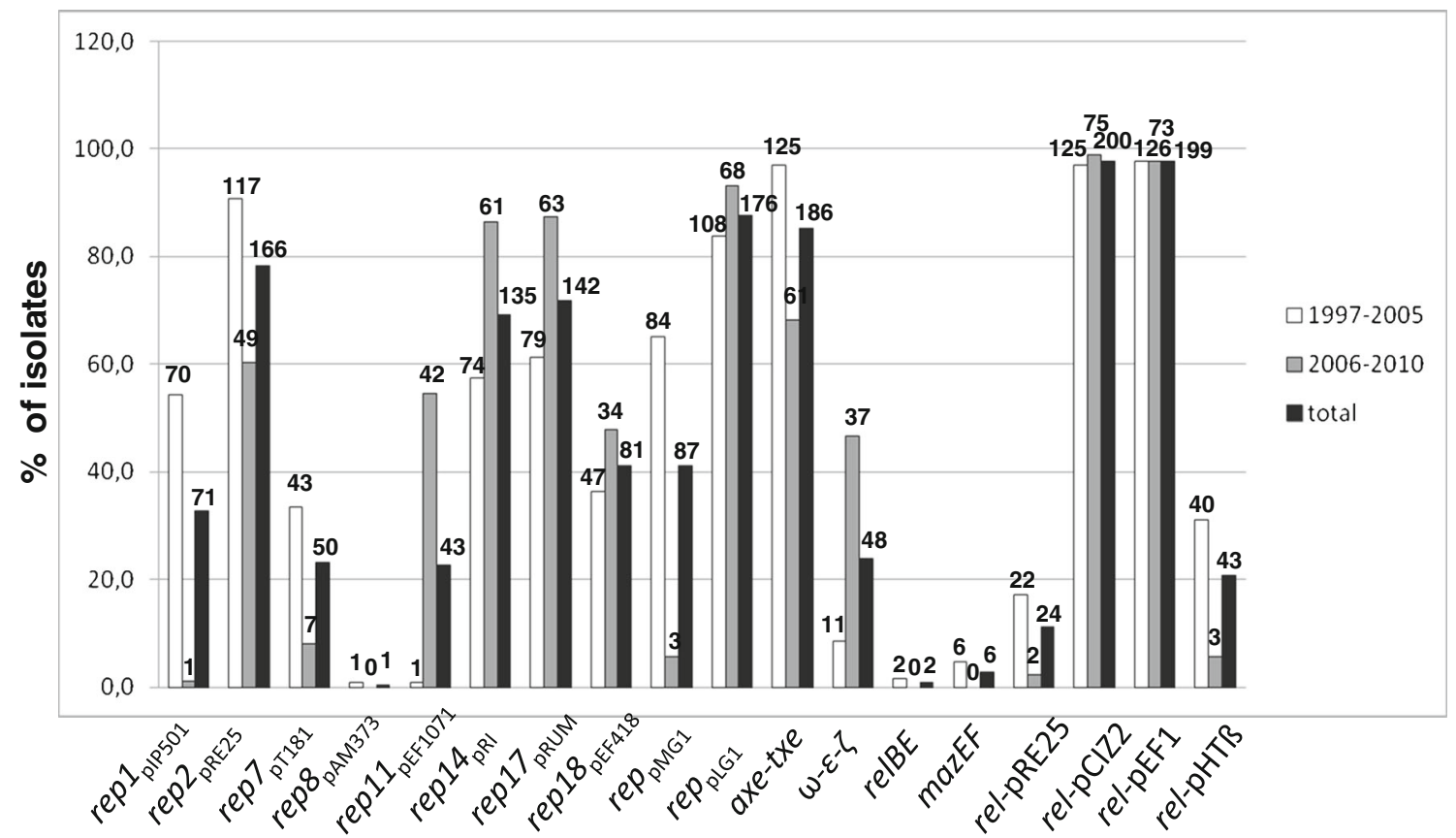

Fig. 2 Plasmid-associated gene distribution among Polish VREfm VanA. Number of isolates with a particular gene given above the graph bars 
were commonly carried by vanA-plasmids ( 35 and 32 plasmids, respectively). The $\omega-\varepsilon-\zeta$ system was characteristic for rep $2_{\mathrm{pRE} 25}$ plasmids and axe-txe for rep $17_{\mathrm{pRUM}}$ plasmids ( 71.4 and $62.9 \%$ of the respective $v a n A$-plasmids). The gene specifying pEF1-relaxase was located on 11 vanA-plasmids $(12.8 \%)$, with various rep types. Some of the presumed genetic events, that could be inferred on the basis of these analyses, include examples of transposon evolution within an enterococcal strain, Tn1546 transposition among plasmids, conjugative transfer of plasmids, and their changes such as recombination or chromosomal integration as proposed in Table 2.

\section{Discussion}

Currently, VREfm play an increasingly important role in nosocomial infections and are considered alert pathogens [29], with vanA as a main determinant of this phenotype within many countries [30]. In Poland VRE remain less prevalent than in the United States or some European countries, e.g. our recent study revealed $7 \%$ vancomycin-resistance among invasive E. faecium collected during 2010-2011 [31]. Although we observed an increasing prevalence of VanB E. faecium [17], VanA is still most frequent among Polish VREfm ([31] and NRCST unpublished observations). In the present study we aimed at the characterization of clonality of VanA-VREfm and genetic elements associated with this resistance determinant. Numerous reports show that in the case of human nosocomial infections vancomycin resistance is almost exclusively acquired by the hospital-adapted meroclone of E. faecium, now widespread all over the world $[2,3]$ and prevalent among invasive E. faecium in Polish hospitals [31]. In this study, the vanA determinant was carried by representatives of this meroclone with only a few exceptions limited to the 1997-2005 period. These isolates might represent intermediates, by which glycopeptides resistance determinants were introduced into hospitals. All isolates belonging to hospital meroclone, as expected, were resistant to both ampicillin and ciprofloxacin, and enriched in putative virulence traits / markers such as IS16, esp $p_{\mathrm{Efm}}$, int $A_{\mathrm{Efm}}$ and pili genes. The population structure determined for Polish VREfm VanA closely resembled these of hospital-associated $E$. faecium in other countries. High diversity of STs/MTs is consistent with the presence of polyclonal hospital population of E. faecium that subsequently acquires vancomycin resistance determinants $[13,14]$. The vast majority of isolates grouped into hospital lineage 17/18, mostly represented by STs $17,117,18$, 132, 202 and lineage 78, which included STs 78, 192 and 412. In contrast to several other countries, where ST203 and ST16 constituted a significant proportion of hospital E. faecium [3, $14,32,33]$, in our population only one representative of ST16 was found and ST203 was completely absent. The characteristic change in the proportion of isolates belonging to lineage $17 / 18$ and lineage 78 was observed since the year 2005 when lineage 78 started to be significantly more frequent in Poland. Our results are in agreement with observations made in other studies, suggesting waves of successful E. faecium, first from lineage 17/18 and followed by lineage 78 strains $[4,34]$. This population shift, apparent in MLST and MLVA, was additionally associated with a change in plasmidome composition and observed decreased resistance levels to tetracycline and aminoglycosides.

Diversity of Tn1546 in VREfm is typical for this transposon, as reported by others $[13,14]$. Nevertheless, in the present study we observed several new variants of $\operatorname{Tn} 1546$. VanA transposons indistinguishable from the $\mathrm{Tn} 1546 \mathrm{~A} 1$ prototype [12] were frequently encountered in Europe, especially in the late 1990s and 2000s [14, 27]. This type and its mutational derivatives (A2-A6) were ubiquitous among early VREfm in our study. Single-nucleotide T insertion between nt 90639064 in the van $Y$ gene of B4 type of transposon resulted in a translational frameshift and a truncated translation product. This change, however, did not abolish the glycopeptide resistance. VanY is a membrane-associated D,D-carboxypeptidase that hydrolyses the C-terminal D-Ala or D-Lac residue of peptidoglycan precursors but lacks transpeptidase activity. VanY, together with VanZ, represent accessory proteins, which are not required for the expression of glycopeptide resistance but increase its level [35]. Isolates with a deletion of $\operatorname{van} Y$ gene showed lower resistance levels to teicoplanin, likely due to the diminished transcription of $\operatorname{van} Z$ while point mutations in van $Y$, observed so far were not associated with a loss of protein function $[27,36]$.

Activity of various ISs represented a very important factor, contributing to the formation of several novel transposon types. IS 1216, the most common IS in our study, characteristic for B-types, was detected at various positions of the transposon, and its insertion often resulted in deletions of adjacent sequences in ORF2, vanX and the van $X$-van $Y$ intergenic region, as observed by others [13, 27]. The BI, BBI, BBBI types, apart from IS1216, exhibited the concomitant presence of a IS1216V-IS3-like element, originally reported in 1995 [37]. Since then, this element was described in several studies, which reported intact as well as a $5^{\prime}$-truncated IS3-like sequence [27, 38], both of which were also detected in our study. The Ctype, harbouring IS1251, was relatively frequent and the integration sites of this IS were identical to those published by others $[14,37,39]$. Sequencing analysis allowed discerning the C1-type, specific for Krakow hospitals and the C2-type, found in other cities. The D type transposon, containing ISEfa5, to our knowledge, represents the first example of this variant outside of South America [34]. Type E represents the first insertion of ISEfa4 in the van $X$-van $Y$ intergenic region. This IS was described 


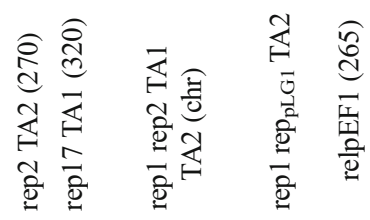

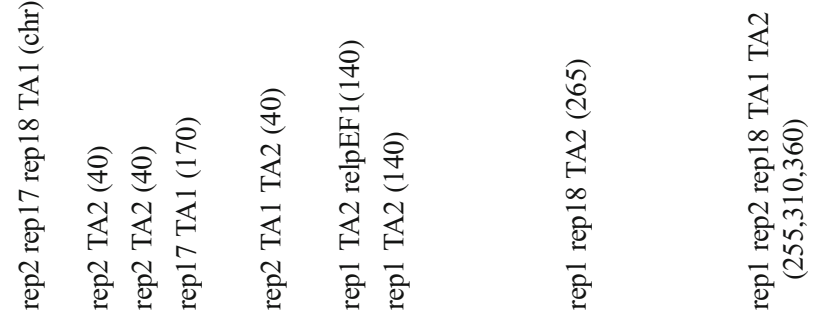

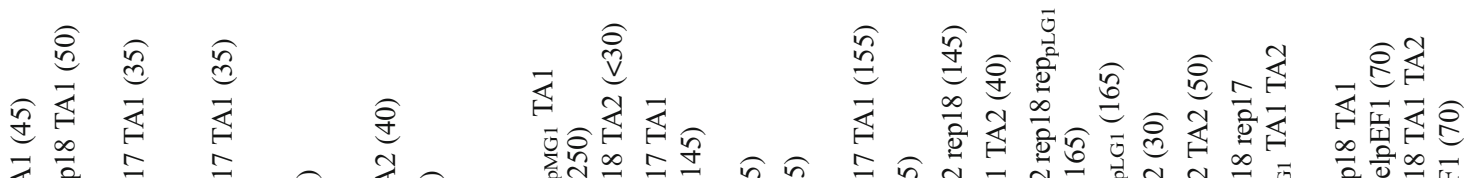

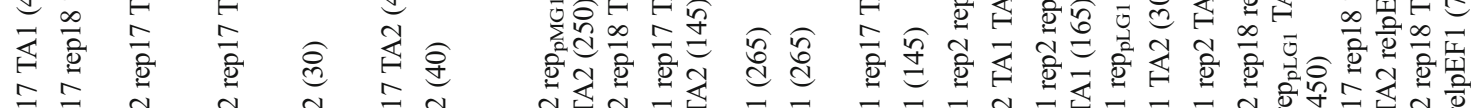

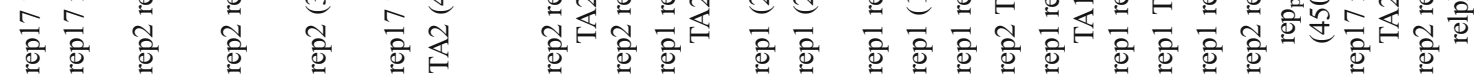

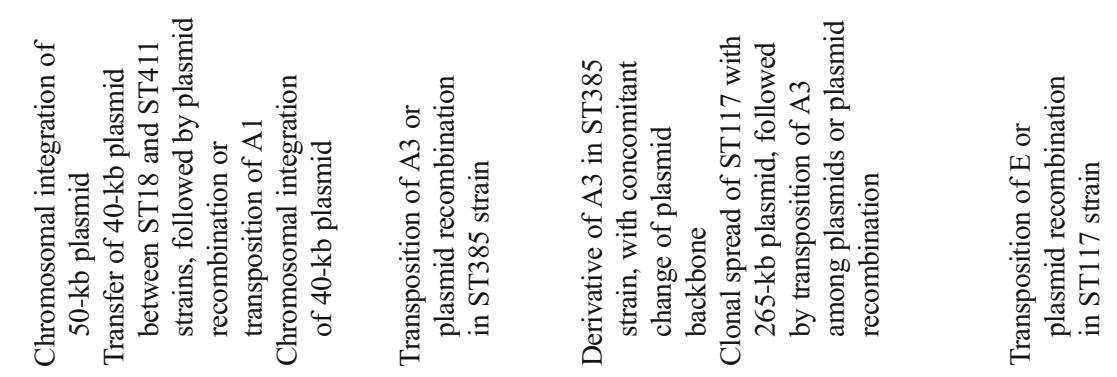

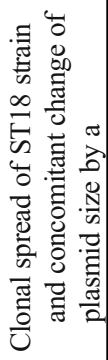

$\frac{0}{10}$

क्षे क्षे क्षे

ह.

$\begin{array}{lll}y & 1 & 1 \\ 0 & 2 & 2\end{array}$

है ?

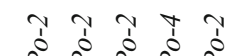

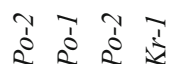

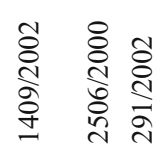
竞蒿

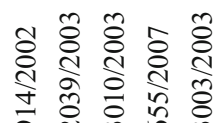

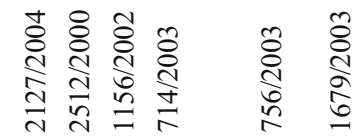




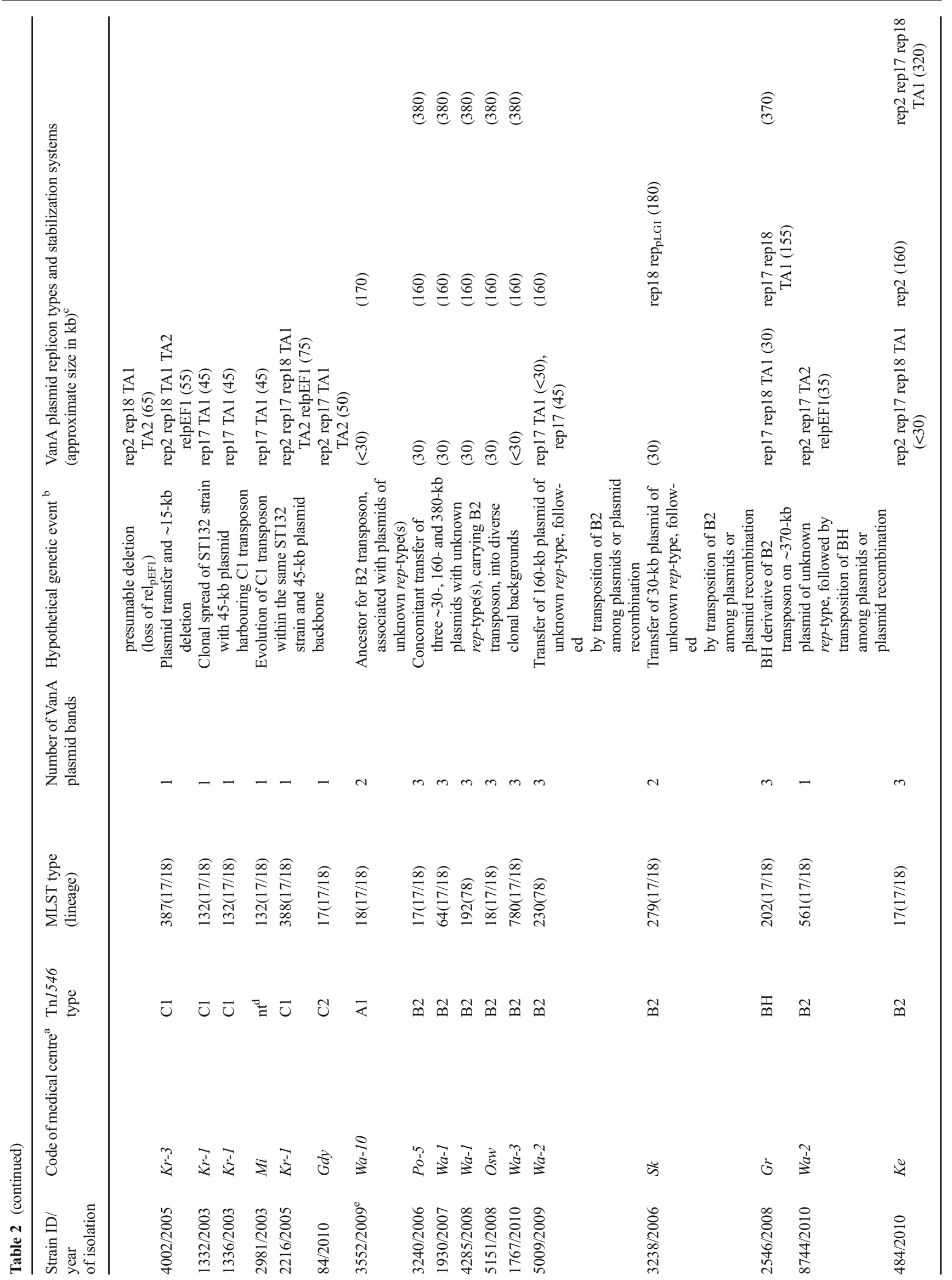




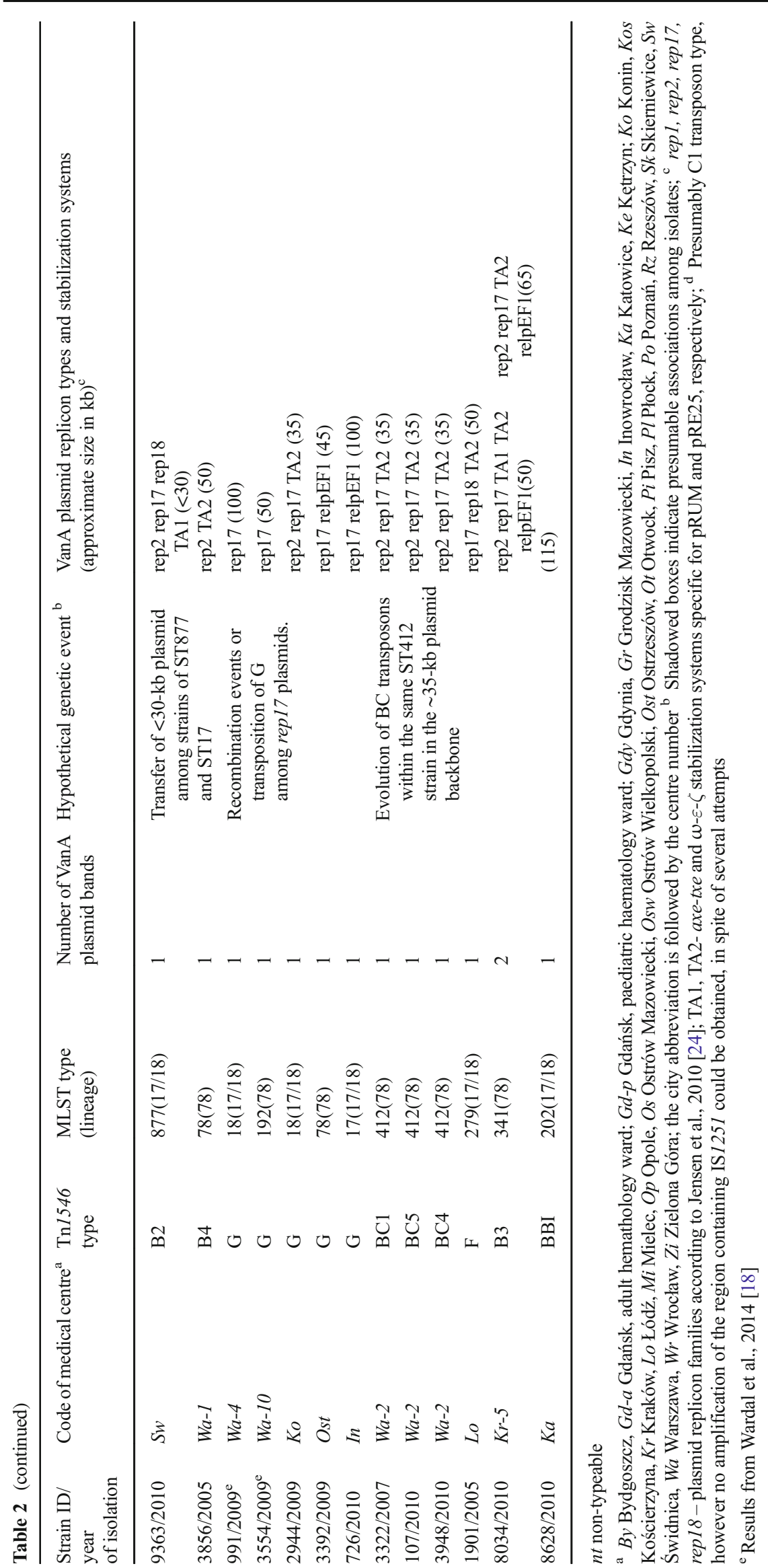


earlier in $\operatorname{orf} 2$-vanR and vanS-vanR intergenic regions [40, 41], as well as within IS1542 [42]. The F type harboured ISEfm2, representative of the IS256 family. Thus far, in enterococci this IS has been solely observed inserted between orf13 and tetS within CTn6000 transposon [43]. In our study, we report for the first time the insertion of ISEfm 2 into Tn1546. The G type transposon with ISEfI, reported earlier for the VREfm outbreak in two neighbouring Warsaw medical centres in 2009 [18] was additionally detected in isolates from 2009 to 2010 derived from seven different cities, which may indicate its multicenter spread. Integration of the ISEfm1-like element, belonging to the IS982 family in the BH type, represents yet another novel insertion event in $\operatorname{Tn} 1546$. The presence of ISEfm1 was described previously in the $\operatorname{van} X$-van $Y$ intergenic region [44], as well as within the vanD operon [45]. Complex analysis of transposon structures described in our study revealed the potential scheme of their hypothetical evolution among Polish VREfm. In this scenario, we propose the A1 type as presumable ancestor variant, with remaining types being its direct or indirect derivatives (Fig. 3).

The vanA determinants are almost exclusively located on plasmids and these elements play a very important role in the spread of glycopeptides resistance [46]. Our results show that the Polish VREfm population is enriched in plasmid replicons of different families including megaplasmids, Inc18-, pRUM- and pMG1/ pHT-like plasmids, encountered in VanA-VREfm in other countries [16, 46, 47]. Size variation of vanA-plasmids, even within the same family indicates their flexibility, and identification of multiple rep types in a single plasmid suggests a common presence of plasmid cointegrates. We observed an interesting change in the VanA-associated plasmidome between early (1997-2005) and more recent (2006-2010) isolates. In particular, rep1-vanA replicons were quite abundant among early isolates and typically located on plasmids over $140 \mathrm{bp}$ in size. Together with rep2-vanA replicons they represent the Inc18 family, associated with $\operatorname{Tn} 1546$ elements among clinical E. faecium in Europe [16, 47]. Another shift in plasmidome composition between early and recent isolates was shown for pMG1 replicons, present exclusively among early VREfm. High prevalence of pMG1-like elements was observed among VREfm in the United States and Japan, where they contributed to the spread of both aminoglycoside and glycopeptide resistance [46]. Apart from Inc18 plasmids, the

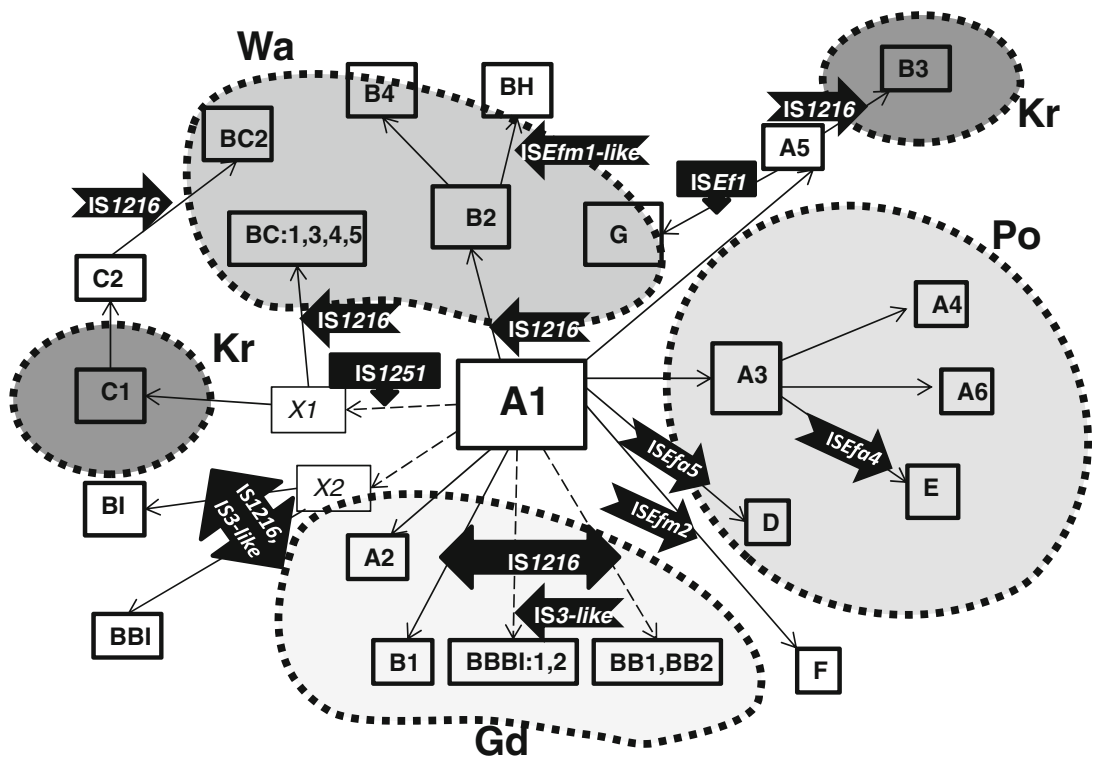

Fig. 3 Hypothetical evolution of Tn1546 structures among Polish VREfm VanA. Type A1, found in different cities, is a presumable ancestor variant with remaining types being its direct or indirect derivatives. Types A2, A3 and A5 developed by point mutations in $w t$ type. A4 developed from A3 through single deletion events in the vanSvan $\mathrm{H}$ intergenic region. A6 is an A3 derivative that lacks ca. $1900 \mathrm{bps}$ in the $5^{\prime}$ end. The E type transposon, a third potential derivative of A3, arose through acquisition of ISEfa 4 between $\operatorname{vanX}$ and $\operatorname{van} Y$. A3 and its derivatives were typical for Poznań (Po) medical centres. B3 and G variants presumably developed from A5 after insertion events of IS1216 and ISEf within vanX-vanY intergenic region in Kraków $(\mathrm{Kr})$ and Warsaw (Wa), respectively. The ubiquitous B2 type, typical for Warsaw, probably emerged from a single insertion event of IS 1216 within the A1 type with a concomitant deletion of the $5^{\prime}$ end of the transposon. The B4 (additional single nucleotide insertion within vanY) and BH (ISEfml-like insertion between $\operatorname{van} X$ and $\operatorname{van} Y$ ) types represent possible derivatives of B2. The $\mathrm{B} 1, \mathrm{D}$ and $\mathrm{F}$ transposon types are potential derivatives of $\mathrm{A} 1$ formed by IS1216, ISEfa5 and ISEfm2 insertions, respectively. Another group of transposon variants, encompassing types BI, BBI, BBBI1, BBBI2, BB1 and BB2 emerged through complex insertion and deletion events in different regions of $w t$ transposon promoted mostly by IS1216 elements. This group was detected mainly in Gdańsk (Gd). The activity of another insertion sequence, IS1251, followed by IS1216 insertions and several point mutations resulted in the formation of C- and BC-types in Kraków and Warsaw, respectively 
pRUM derivatives constitute the second main carrier of vancomycin resistance among the contemporary $E$. faecium isolates $[16,46]$. Plasmids with the pRUM-like rep can be divided into two groups, one with axe-txe genes and mob regions from the staphylococcal pC223 plasmid and the other with relaxase from $\mathrm{pEF} 1$ and lacking axe-txe $[15,16,46]$. Our results indicate that representatives of both these groups are present among Polish VREfm. Additionally, we observed plasmids with unknown rep types among isolates obtained since 2006, which suggests the appearance of a new vanA-plasmid type(s), not included in the available classification scheme [24] and which will be a subject to further studies.

Finally, the analysis of PFGE-S1 hybridization results in the context of epidemiological information, determined Tn1546 types and the clonal background of the isolates, which revealed a high complexity of genetic events involving VREfm with VanA phenotype and resulting in the dissemination of this type of resistance. As these 52 isolates were pre-selected for a maximal representation of the collection diversity, only a few examples of clonal spread were observed, such as dissemination of ST132 strain with a $45-\mathrm{kb}$ plasmid harbouring $\mathrm{C} 1$ transposon in a Krakow hospital (Table 2). The role of VREfm clonal spread in Poland, however, had been demonstrated before in our outbreak studies [18, 39, 48]. Particular types of transposons in the analysed group were frequently associated with various plasmid vectors. This situation may have resulted from transposition of Tn1546 among plasmids [12], promoted by integration 'hot-spots' [49] and from the recombination processes among enterococcal plasmids $[15,50]$. The present study also provided examples of involvement of plasmids as vectors of vancomycin resistance, by demonstrating the presence of plasmids of the same size and with the same transposon types and plasmid-specific genes in different strains, as found in other studies $[15,51]$. Occasionally, vanA-plasmids appeared to be integrated into bacterial chromosome, in agreement with other observations [52]. Further detailed studies employing extensive sequencing are indispensable to fully elucidate the events involving genetic elements engaged in the dissemination of the vanA gene cluster in the population of Polish VREfm.

In conclusion, the VREfm of the VanA phenotype collected in our country over the period 1997-2010 represent a highly variable group in the respect of their clonal composition, plasmid content and structures of $\operatorname{Tn} 1546$, a direct carrier of vanA genes. High genetic plasticity of these organisms, together with a rapid global spread of successful hospital-adapted enterococcal clones constitute a significant and continuously increasing epidemiological threat for human health. Thus, both epidemiological situation concerning VREfm as well as genetic elements and strains associated with VanA vancomycin resistance warrant further studies.
Acknowledgments We thank all Polish microbiologists who sent VREm isolates to our laboratory, Janetta Top for assigning new alleles, STs and MTs, and Kenneth Van Horn for critical reading of the manuscript. This publication made use of the Enterococcus faecium MLST website (http://efaecium.mlst.net/) hosted at Imperial College of the University of Oxford and funded by the Wellcome Trust.

\section{Compliance with ethical standards}

Funding This work was supported by the grant N N401588540 from the Narodowe Centrum Nauki (NCN), Poland, by the MIKROBANK funding from the Ministry of Science and Higher Education, Poland, and by a statutory funding from the Ministry of Science and Higher Education, Poland.

Conflict of interest The authors declare that they have no conflict of interest.

Ethical approval and informed consent Isolates were obtained as a part of routine activity of the NRCST and were analysed anonymously in a retrospective manner. Ethical approval and informed consent were thus not required.

Open Access This article is distributed under the terms of the Creative Commons Attribution 4.0 International License (http:// creativecommons.org/licenses/by/4.0/), which permits unrestricted use, distribution, and reproduction in any medium, provided you give appropriate credit to the original author(s) and the source, provide a link to the Creative Commons license, and indicate if changes were made.

\section{References}

1. Hryniewicz W, Szczypa K, Bronk M, Samet A, Hellmann A, Trzcinski K (1999) First report of vancomycin-resistant Enterococcus faecium isolated in Poland. Clin Microbiol Infect 5(8):503-505

2. Willems RJ, Top J, van Santen M, Robinson DA, Coque TM, Baquero F, Grundmann H, Bonten MJ (2005) Global spread of vancomycin-resistant Enterococcus faecium from distinct nosocomial genetic complex. Emerg Infect Dis 11(6):821-828. doi:10.3201/eid1106.041204

3. Willems RJ, Hanage WP, Bessen DE, Feil EJ (2011) Population biology of gram-positive pathogens: high-risk clones for dissemination of antibiotic resistance. FEMS Microbiol Rev 35(5):872900. doi:10.1111/j.1574-6976.2011.00284.x

4. Willems RJ, Top J, van Schaik W, Leavis H, Bonten M, Siren J, Hanage WP, Corander J (2012) Restricted gene flow among hospital subpopulations of Enterococcus faecium. MBio 3(4):e0015100112. doi:10.1128/mBio.00151-12

5. Hendrickx AP, Bonten MJ, van Luit-Asbroek M, Schapendonk CM, Kragten AH, Willems RJ (2008) Expression of two distinct types of pili by a hospital-acquired Enterococcus faecium isolate. Microbiology 154(Pt 10):3212-3223. doi:10.1099/mic.0.2008 /020891-0

6. Heikens E, van Schaik W, Leavis HL, Bonten MJ, Willems RJ (2008) Identification of a novel genomic island specific to hospital-acquired clonal complex 17 enterococcus faecium isolates. Appl Environ Microbiol 74(22):7094-7097. doi:10.1128 /AEM.01378-08

7. 7. Lebreton F, van Schaik W, McGuire AM, Godfrey P, Griggs A, Mazumdar V, Corander J, Cheng L, Saif S, Young S, Zeng Q, 
Wortman J, Birren B, Willems RJ, Earl AM, Gilmore MS (2013) Emergence of epidemic multidrug-resistant Enterococcus faecium from animal and commensal strains. MBio 4(4). doi:10.1128 /mBio.00534-13

8. Top J, Sinnige JC, Majoor EA, Bonten MJ, Willems RJ, van Schaik $\mathrm{W}$ (2011) The recombinase IntA is required for excision of espcontaining ICEEfm1 in Enterococcus faecium. J Bacteriol 193(4): 1003-1006. doi:10.1128/JB.00952-10

9. Willems RJL, Homan W, Top J, van Santen-Verheuvel M, Tribe D, Manzioros X, Gaillard C, Vandenbroucke-Grauls CMJE, Mascini EM, van Kregten E, van Embden JDA, Bonten MJM (2001) Variant esp gene as a marker of a distinct genetic lineage of vancomycinresistant Enterococcus faecium spreading in hospitals. Lancet 357(9259):853-855. doi:10.1016/s0140-6736(00)04205-7

10. Werner G, Fleige C, Geringer U, van Schaik W, Klare I, Witte W (2011) IS element IS16 as a molecular screening tool to identify hospital-associated strains of Enterococcus faecium. BMC Infect Dis 11:80. doi:10.1186/1471-2334-11-80

11. Courvalin P (2005) Genetics of glycopeptide resistance in grampositive pathogens. Int J Med Microbiol 294(8):479-486. doi:10.1016/j.ijmm.2004.10.002

12. Arthur M, Molinas C, Depardieu F, Courvalin P (1993) Characterization of $\operatorname{Tn} 1546$, a Tn3-related transposon conferring glycopeptide resistance by synthesis of depsipeptide peptidoglycan precursors in Enterococcus faecium BM4147. J Bacteriol 175(1): $117-127$

13. Talebi M, Pourshafie MR, Katouli M, Mollby R (2008) Molecular structure and transferability of Tn1546-like elements in Enterococcus faecium isolates from clinical, sewage, and surface water samples in Iran. Appl Environ Microbiol 74(5):1350-1356. doi:10.1128/AEM.02254-07

14. Werner G, Klare I, Fleige C, Witte W (2008) Increasing rates of vancomycin resistance among Enterococcus faecium isolated from German hospitals between 2004 and 2006 are due to wide clonal dissemination of vancomycin-resistant enterococci and horizontal spread of vanA clusters. Int J Med Microbiol 298(5-6):515-527. doi:10.1016/j.ijmm.2007.05.008

15. Freitas AR, Novais C, Tedim AP, Francia MV, Baquero F, Peixe L, Coque TM (2013) Microevolutionary events involving narrow host plasmids influences local fixation of vancomycin-resistance in Enterococcus populations. PLoS One 8(3):e60589. doi:10.1371 /journal.pone.0060589

16. Rosvoll TC, Pedersen T, Sletvold H, Johnsen PJ, Sollid JE, Simonsen GS, Jensen LB, Nielsen KM, Sundsfjord A (2010) PCR-based plasmid typing in Enterococcus faecium strains reveals widely distributed pRE25-, pRUM-, pIP501- and pHTbeta-related replicons associated with glycopeptide resistance and stabilizing toxin-antitoxin systems. FEMS Immunol Med Microbiol 58(2): 254-268. doi:10.1111/j.1574-695X.2009.00633.x

17. Sadowy E, Sienko A, Gawryszewska I, Bojarska A, Malinowska K, Hryniewicz W (2013) High abundance and diversity of antimicrobial resistance determinants among early vancomycin-resistant Enterococcus faecium in Poland. Eur J Clin Microbiol Infect Dis 32(9):1193-1203. doi:10.1007/s10096-013-1868-y

18. Wardal E, Markowska K, Zabicka D, Wroblewska M, Giemza M, Mik E, Polowniak-Pracka H, Wozniak A, Hryniewicz W, Sadowy E (2014) Molecular analysis of vanA outbreak of Enterococcus faecium in two Warsaw hospitals: the importance of mobile genetic elements. Biomed Res Int 2014:575367. doi:10.1155/2014/575367

19. CLSI (2015) Clinical and Laboratory Standards Institute (CLSI) (2015) Performance standards for antimicrobial susceptibility testing; 25th informational supplement. CLSI document M100-S20. CLSI, Wayne, PA

20. Magiorakos AP, Srinivasan A, Carey RB, Carmeli Y, Falagas ME, Giske CG, Harbarth S, Hindler JF, Kahlmeter G, Olsson-Liljequist B, Paterson DL, Rice LB, Stelling J, Struelens MJ, Vatopoulos A,
Weber JT, Monnet DL (2012) Multidrug-resistant, extensively drug-resistant and pandrug-resistant bacteria: an international expert proposal for interim standard definitions for acquired resistance. Clin Microbiol Infect 18(3):268-281. doi:10.1111/j.14690691.2011.03570.x

21. Clark NC, Cooksey RC, Hill BC, Swenson JM, Tenover FC (1993) Characterization of glycopeptide-resistant enterococci from U.S. hospitals. Antimicrob Agents Chemother 37(11):2311-2317

22. Top J, Schouls LM, Bonten MJ, Willems RJ (2004) Multiple-locus variable-number tandem repeat analysis, a novel typing scheme to study the genetic relatedness and epidemiology of Enterococcus faecium isolates. J Clin Microbiol 42(10):4503-4511. doi:10.1128 /JCM.42.10.4503-4511.2004

23. Homan WL, Tribe D, Poznanski S, Li M, Hogg G, Spalburg E, Van Embden JD, Willems RJ (2002) Multilocus sequence typing scheme for Enterococcus faecium. J Clin Microbiol 40(6):19631971

24. Jensen LB, Garcia-Migura L, Valenzuela AJ, Lohr M, Hasman H, Aarestrup FM (2010) A classification system for plasmids from enterococci and other Gram-positive bacteria. J Microbiol Methods 80(1):25-43. doi:10.1016/j.mimet.2009.10.012

25. Wardal E, Gawryszewska I, Hryniewicz W, Sadowy E (2013) Abundance and diversity of plasmid-associated genes among clinical isolates of Enterococcus faecalis. Plasmid 70(3):329-342. doi:10.1016/j.plasmid.2013.07.003

26. Barton BM, Harding GP, Zuccarelli AJ (1995) A general method for detecting and sizing large plasmids. Anal Biochem 226(2):235240. doi:10.1006/abio.1995.1220

27. Willems RJ, Top J, van den Braak N, van Belkum A, Mevius DJ, Hendriks G, van Santen-Verheuvel M, van Embden JD (1999) Molecular diversity and evolutionary relationships of Tn1546-like elements in enterococci from humans and animals. Antimicrob Agents Chemother 43(3):483-491

28. Jensen LB, Ahrens P, Dons L, Jones RN, Hammerum AM, Aarestrup FM (1998) Molecular analysis of Tn1546 in Enterococcus faecium isolated from animals and humans. J Clin Microbiol 36(2):437-442

29. Boucher HW, Talbot GH, Bradley JS, Edwards JE, Gilbert D, Rice LB, Scheld M, Spellberg B, Bartlett J (2009) Bad bugs, no drugs: no ESKAPE! An update from the Infectious Diseases Society of America. Clin Infect Dis 48(1):1-12. doi:10.1086/595011

30. Werner G, Coque TM, Hammerum AM, Hope R, Hryniewicz W, Johnson A, Klare I, Kristinsson KG, Leclercq R, Lester CH, Lillie M, Novais C, Olsson-Liljequist B, Peixe LV, Sadowy E, Simonsen GS, Top J, Vuopio-Varkila J, Willems RJ, Witte W, Woodford N (2008) Emergence and spread of vancomycin resistance among enterococci in Europe. Euro Surveill 13(47)

31. Gawryszewska I, Zabicka D, Bojarska K, Malinowska K, Hryniewicz W, Sadowy E (2016) Invasive enterococcal infections in Poland: the current epidemiological situation. Eur J Clin Microbiol Infect Dis 35(5):847-856. doi:10.1007/s10096-0162607-y

32. Johnson PD, Ballard SA, Grabsch EA, Stinear TP, Seemann T, Young HL, Grayson ML, Howden BP (2010) A sustained hospital outbreak of vancomycin-resistant Enterococcus faecium bacteremia due to emergence of $\operatorname{vanB} E$. faecium sequence type 203. J Infect Dis 202(8):1278-1286. doi:10.1086/656319

33. Zheng B, Tomita H, Xiao YH, Wang S, Li Y, Ike Y (2007) Molecular characterization of vancomycin-resistant enterococcus faecium isolates from mainland China. J Clin Microbiol 45(9): 2813-2818. doi:10.1128/JCM.00457-07

34. Khan MA, Northwood JB, Loor RG, Tholen AT, Riera E, Falcon M, Paraguayan Antimicrobial N, van Belkum A, van Westreenen M, Hays JP (2010) High prevalence of ST-78 infection-associated vancomycin-resistant Enterococcus faecium from hospitals in 
Asuncion, Paraguay. Clin Microbiol Infect 16(6):624-627. doi:10.1111/j.1469-0691.2009.02898.x

35. Arthur M, Depardieu F, Reynolds P, Courvalin P (1996) Quantitative analysis of the metabolism of soluble cytoplasmic peptidoglycan precursors of glycopeptide-resistant enterococci. Mol Microbiol 21(1):33-44. doi:10.1046/j.13652958.1996.00617.x

36. Khan SA, Sung K, Layton S, Nawaz MS (2008) Heteroresistance to vancomycin and novel point mutations in Tn1546 of Enterococcus faecium ATCC 51559. Int J Antimicrob Agents 31(1):27-36. doi:10.1016/j.ijantimicag.2007.08.007

37. Handwerger S, Skoble J (1995) Identification of chromosomal mobile element conferring high-level vancomycin resistance in Enterococcus faecium. Antimicrob Agents Chemother 39(11): 2446-2453

38. Jung WK, Hong SK, Lim JY, Lim SK, Kwon NH, Kim JM, Koo HC, Kim SH, Seo KS, Ike Y, Tanimoto K, Park YH (2006) Phenotypic and genetic characterization of vancomycin-resistant enterococci from hospitalized humans and from poultry in Korea. FEMS Microbiol Lett 260(2):193-200. doi:10.1111/j.15746968.2006.00311.x

39. Kawalec M, Kedzierska J, Gajda A, Sadowy E, Wegrzyn J, Naser S, Skotnicki AB, Gniadkowski M, Hryniewicz W (2007) Hospital outbreak of vancomycin-resistant enterococci caused by a single clone of Enterococcus raffinosus and several clones of Enterococcus faecium. Clin Microbiol Infect 13(9):893-901. doi:10.1111/j.1469-0691.2007.01774.x

40. Gu L, Cao B, Liu Y, Guo P, Song S, Li R, Dai H, Wang C (2009) A new $\operatorname{Tn} 1546$ type of VanB phenotype-vanA genotype vancomycinresistant Enterococcus faecium isolates in mainland China. Diagn Microbiol Infect Dis 63(1):70-75. doi:10.1016/j. diagmicrobio.2008.08.018

41. Depardieu F, Reynolds PE, Courvalin P (2003) VanD-type vancomycin-resistant Enterococcus faecium 10/96A. Antimicrob Agents Chemother 47(1):7-18. doi:10.1128/aac.47.1.7-18.2003

42. Cha JO, Yoo JI, Kim HK, Kim HS, Yoo JS, Lee YS, Jung YH (2013) Diversity of Tn1546 in vanA-positive Enterococcus faecium clinical isolates with VanA, VanB, and VanD phenotypes and susceptibility to vancomycin. J Appl Microbiol 115(4):969-976. doi:10.1111/jam.12300

43. Novais C, Freitas AR, Silveira E, Baquero F, Peixe L, Roberts AP, Coque TM (2012) Different genetic supports for the tet(S) gene in enterococci. Antimicrob Agents Chemother 56(11):6014-6018. doi:10.1128/AAC.00758-12

44. Novais C, Freitas AR, Sousa JC, Baquero F, Coque TM, Peixe LV (2008) Diversity of Tn1546 and its role in the dissemination of vancomycin-resistant enterococci in Portugal. Antimicrob Agents Chemother 52(3):1001-1008. doi:10.1128/AAC.00999-07
45. Boyd DA, Conly J, Dedier H, Peters G, Robertson L, Slater E, Mulvey MR (2000) Molecular characterization of the vanD gene cluster and a novel insertion element in a vancomycin-resistant Enterococcus isolated in Canada. J Clin Microbiol 38(6):23922394

46. Lanza VF, Tedim AP, Martinez JL, Baquero F, Coque TM (2015) The plasmidome of firmicutes: impact on the emergence and the spread of resistance to antimicrobials. Microbiol Spectr 3 (2): PLAS-0039-2014. doi:10.1128/microbiolspec.PLAS-0039-2014

47. Sletvold H, Johnsen PJ, Wikmark OG, Simonsen GS, Sundsfjord A, Nielsen KM (2010) Tn1546 is part of a larger plasmid-encoded genetic unit horizontally disseminated among clonal Enterococcus faecium lineages. J Antimicrob Chemother 65(9):1894-1906. doi:10.1093/jac/dkq219

48. Kawalec M, Gniadkowski M, Hryniewicz W (2000) Outbreak of vancomycin-resistant enterococci in a hospital in Gdask, Poland, due to horizontal transfer of different Tn1546-like transposon variants and clonal spread of several strains. J Clin Microbiol 38(9): $3317-3322$

49. Garcia-Migura L, Hasman H, Svendsen C, Jensen LB (2008) Relevance of hot spots in the evolution and transmission of Tn1546 in glycopeptide-resistant Enterococcus faecium (GREF) from broiler origin. J Antimicrob Chemother 62(4):681-687. doi:10.1093/jac/dkn265

50. Teuber M, Schwarz F, Perreten V (2003) Molecular structure and evolution of the conjugative multiresistance plasmid pRE25 of Enterococcus faecalis isolated from a raw-fermented sausage. Int J Food Microbiol 88(2-3):325-329

51. Garcia-Migura L, Liebana E, Jensen LB (2007) Transposon characterization of vancomycin-resistant Enterococcus faecium (VREF) and dissemination of resistance associated with transferable plasmids. J Antimicrob Chemother 60(2):263-268. doi:10.1093 /jac/dkm186

52. Paulsen IT, Banerjei L, Myers GS, Nelson KE, Seshadri R, Read TD, Fouts DE, Eisen JA, Gill SR, Heidelberg JF, Tettelin H, Dodson RJ, Umayam L, Brinkac L, Beanan M, Daugherty S, DeBoy RT, Durkin S, Kolonay J, Madupu R, Nelson W, Vamathevan J, Tran B, Upton J, Hansen T, Shetty J, Khouri H, Utterback T, Radune D, Ketchum KA, Dougherty BA, Fraser CM (2003) Role of mobile DNA in the evolution of vancomycinresistant Enterococcus faecalis. Science 299(5615):2071-2074. doi:10.1126/science. 1080613

53. EUCAST (2015) European Committee on Antimicrobial Susceptibility Testing (EUCAST) (2015) Breakpoint tables for interpretation of MICs and zone diameters. Version 5.0, EUCAST, Basel, Switzerland 